\title{
Textile UWB Antenna Bending and Wet Performances
}

\author{
Mai A. R. Osman, ${ }^{1}$ M. K. A. Rahim, ${ }^{1}$ N. A. Samsuri, ${ }^{1}$ M. K. Elbasheer, ${ }^{2}$ and M. E. Alii \\ ${ }^{1}$ Radio Communication Engineering Department (RaCED), Faculty of Electrical Engineering, Universiti Teknologi Malaysia, 81310 \\ Johor, Malaysia \\ ${ }^{2}$ Mechanical Engineering Department, Faculty of Engineering, Sudan University of Science and Technology, Khartoum 407-111, Sudan \\ ${ }^{3}$ Electronic and Electrical Engineering Department, School of Engineering and Built Environment, Edinburgh Napier University, \\ Merchiston Campus, EH10 5DT Edinburgh, UK
}

Correspondence should be addressed to Mai A. R. Osman, mayoya78@gmail.com

Received 15 November 2011; Revised 11 February 2012; Accepted 7 March 2012

Academic Editor: Hendrik Rogier

Copyright ( 2012 Mai A. R. Osman et al. This is an open access article distributed under the Creative Commons Attribution License, which permits unrestricted use, distribution, and reproduction in any medium, provided the original work is properly cited.

The vision and ideas of wearable computing systems describe future electronic systems as an integral part of our everyday clothing that provides the wearer with such intelligent personal assistants. Recently, there has been growing interest in the antenna community to merge between wearable systems technology, ultrawideband (UWB) technology and textile technology. This work aimed to make closer steps towards real wearability by investigating the possibilities of designing wearable UWB antenna where textile materials are used for the substrate as well as the conducting parts of the designed antenna. Two types of conducting materials have been used for conducting parts, while a nonconducting fabric has been used as antenna substrate material. A set of comparative results of the proposed design were presented and discussed. Moreover, effects on the return loss by means of measurements for each fabricated antenna prototype under bent and fully wet conditions were discussed in more details.

\section{Introduction}

Portable electronic devices have become part of everyday human life acting as mobile phones that are quite often carried throughout the day and allow not just telephone calls alone but also provide internet access, multimedia, and personal digital assistant. This form of "always on" and constantly connected status can be considered as a step towards the pervasive computing paradigm. According to that, extensive worldwide research has been carried out on new wearable devices where wearable computers will be capable to perform as ancestors to smart clothes. In that sense, smart clothes will ensure the ability of wearable devices to escape from the confines of the rigid box and hence merge with textile technology. This kind of incorporation of antennas into uniform will add the benefit of eliminating clumsy devices that can be entangled to some extent [1-3]. However, as technologies advances, new and a vast number of potential applications emerged, such as: wireless transactions, general network connections, navigation support, location-based services, tourism, security, emergency, child protection, intelligent transportation system, military applications, smart suits, backpack radar, battlefield personnel care, medical monitoring, smart diagnosis, aging care, biosensors, space applications, and astronaut monitoring.

On the other hand, the key considerations for wearable electronics are to be lightweight, flexible, small size, inexpensive, able to withstand damage from obstacles (robust), and comfortable to wear [4-6]. Since the Federal Communications Commission (FCC) in 2002 approved the commercial use of frequency bands from 3.1 to $10.6 \mathrm{GHz}$ for Ultrawideband(UWB) systems, UWB antennas received more and more attention with the advancement of communication technology [7-9]. The attractive features of UWB antennas, such as low profile, low cost, and radiation properties, do not need to transmit a high-power signal to the receiver, can 


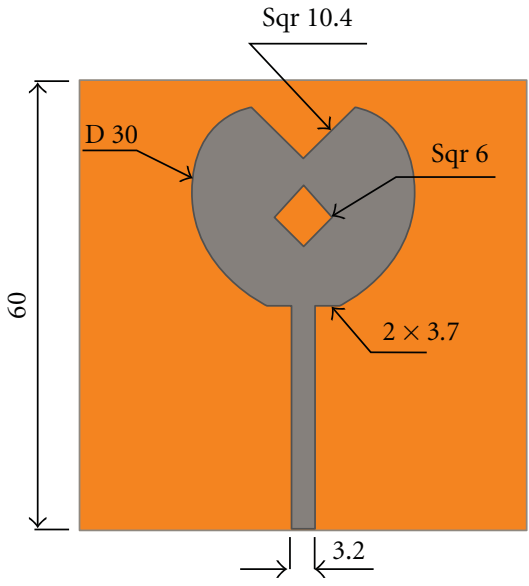

(a)

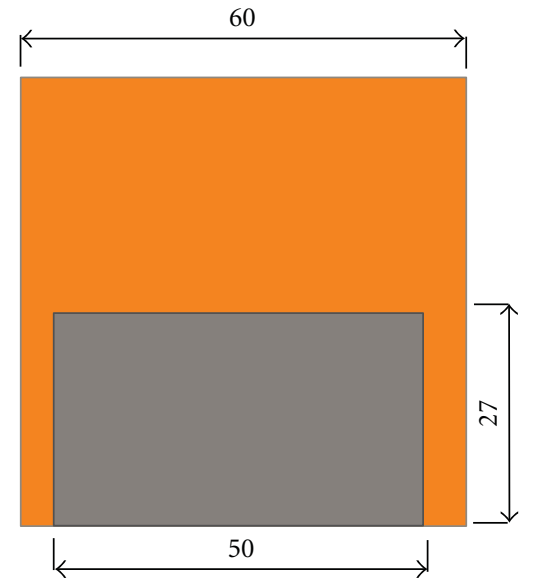

(b)

FIGURE 1: CST model along with the geometry and dimensions in millimetre of the current paper design; (a) front view and (b) back view of the proposed antenna design.

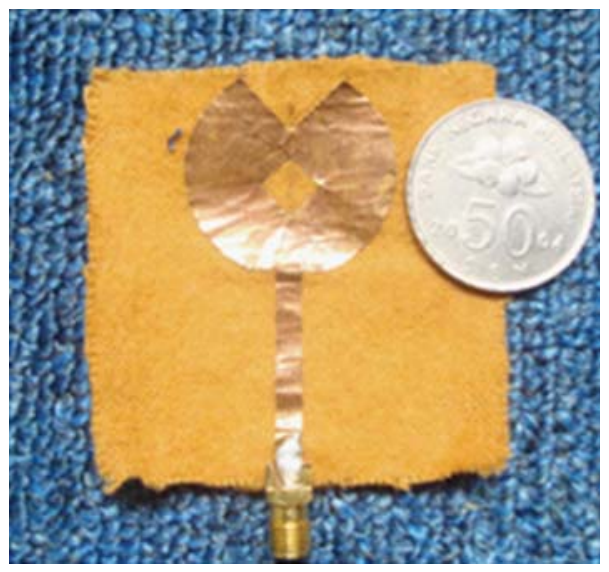

(a)

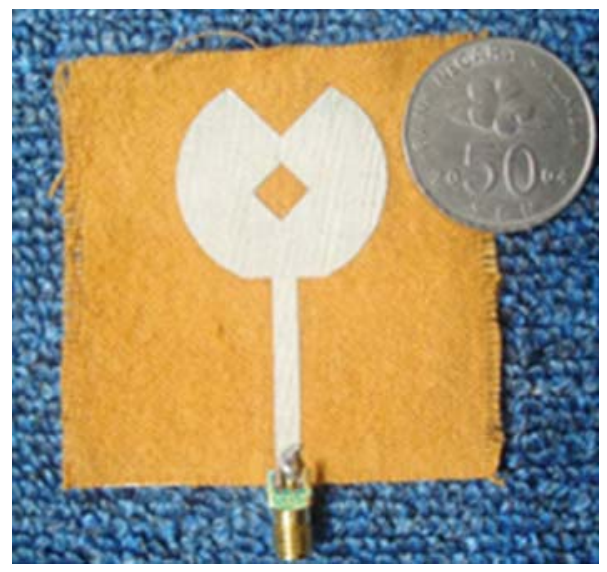

(b)

Figure 2: The fabricated wearable UWB antenna prototypes using flannel fabric with: (a) copper conducting sheet, (b) Shieldit conducting fabric.

have a longer battery life, and the compact size enhanced the possibilities of reducing the wearable devices size and therefore ease the fabrication process $[9,10]$.

Since 1997, wearable telecommunication systems have become popular topics in research institutions. Numerous papers have been published about the design, fabrication and applications of wearable antennas and systems. Some of these developments are highlighted below. Several researches have taken quantum leaps in utilizing textile materials as antenna substrate [10-12]. Wearable antennas have been developed in the form of flexible metal patches on textile substrates [1315]. A dual-band wearable antenna was discussed in detail $[16,17]$. Furthermore, another investigation of using electrotextile materials for designing microstrip patch antenna as well as UWB antenna were reported in $[18,19]$. In addition, UWB sensors and their suitability for medical applications were also considered [20-22]. With all these mentioned findings, markets opened up to a wide range of potential requirements and investigations for these novel materials considering UWB antenna designs and applications. Consistent with all these facts mentioned above, authors of the current paper aimed to make closer steps towards real wearability. Moreover, full success can be achieved only when the antenna and all related components are entirely converted into $100 \%$ textile materials where the use of embedded textile components guarantees washing of the electronic suit and accordingly reuse of it. In this work, a fully textile UWB antenna is presented with detailed discussion about the concept, simulation, as well as manufacturing process. Two types of conducting materials have been used for conducting parts, while a nonconducting fabric has been used as antenna substrate material. In the following sections, materials that have been used to accomplish the wearable antenna design, successive design steps, and a set of comparative results of the proposed design shall be presented. Moreover, effects on the return loss by means of 


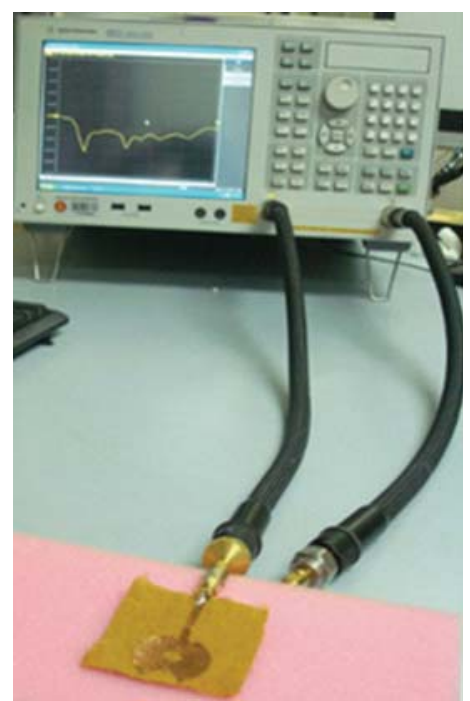

(a)

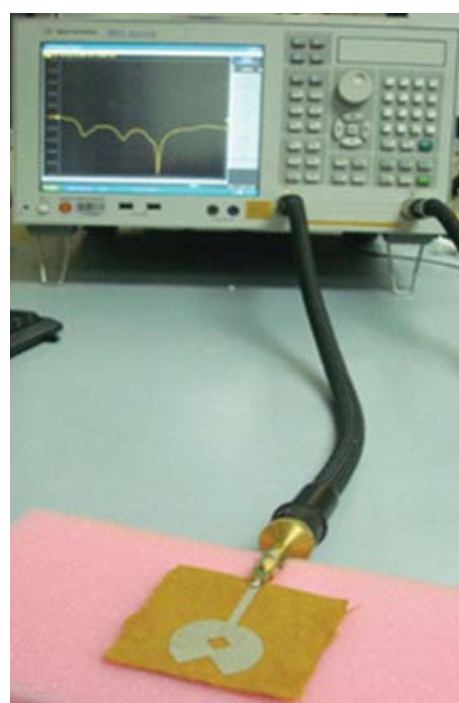

(b)

Figure 3: Snapshot of $\left(\left|S_{11}\right|\right)$ measurement environment of both antenna prototypes using (a) copper conducting tape and (b) Shieldit conducting fabric.

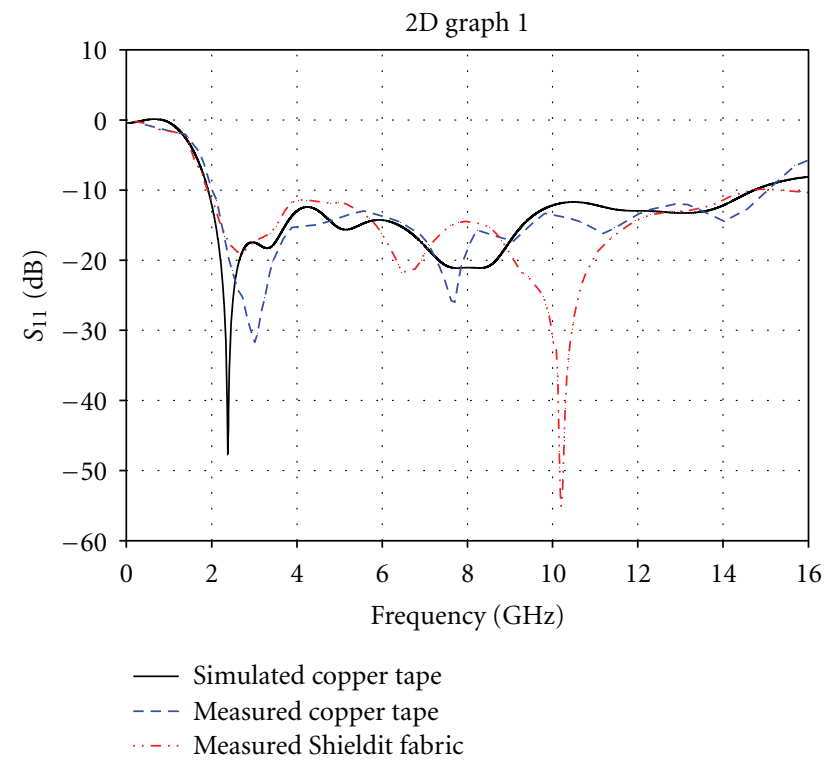

FIGURE 4: Comparison between simulated and measured $\left(\left|S_{11}\right|\right)$ results of the proposed wearable textile UWB antenna design.

measurements for each fabricated antenna prototype under bent and fully wet conditions will be discussed in more details.

\section{Material Selection}

The most important properties of textile materials that are mobilized in wearable applications are flexibility to conform to the body, comfort to touch, and softness. Applications also need to be cost-effective, widely available, allow easy interpretation, and provide consistent results. The terms textile and fabric antenna are used interchangeably here. However, in most cases, textile antenna refers to an antenna, whereas the term fabric relates to the substrate material. In this paper, a fully textile UWB wearable antenna is designed and analyzed. The proposed antenna designs are made from flannel fabric substrate material along with two types of conducting materials that will be discussed in more details in the following sections.

2.1. Substrate Material. For flexible antennas, textile materials form interesting substrates because fabric antennas can be easily integrated into clothes. Textile materials generally have a very low dielectric constant which reduces surface wave losses and improves antenna's impedance bandwidth $[19,20]$. In this work, our study focuses on using flannel fabric as substrate material. Flannel fabric is a kind of $100 \%$ cotton material with smooth, firm, and fluffy surface that made the fabric suitable for wearable applications. Moreover, fabric substrate material features might aid in maintaining the distance to remain constant between the radiating patch and the ground plane in order to control antenna's electrical characteristics. In fact, the smooth and firm surface of fabric substrate material is required to allow conductive sheets to be fastened evenly and stoutly on fabric surface. If the copper sheet detaches merely from one corner and the space between the metal layers varies, the resonant frequency of the proposed antenna changes. The thickness of this fabric is almost $1 \mathrm{~mm}$, but in order to characterize the effect of textile materials accurately, it is important to know its relative permittivity. Thus, using the commercial dielectric probe (reflected method), the measured relative permittivity of flannel fabric covering the frequency range from $300 \mathrm{MHz}$ up to $20 \mathrm{GHz}$ is approximately 1.7 while the loss tangent is about 0.025 . 


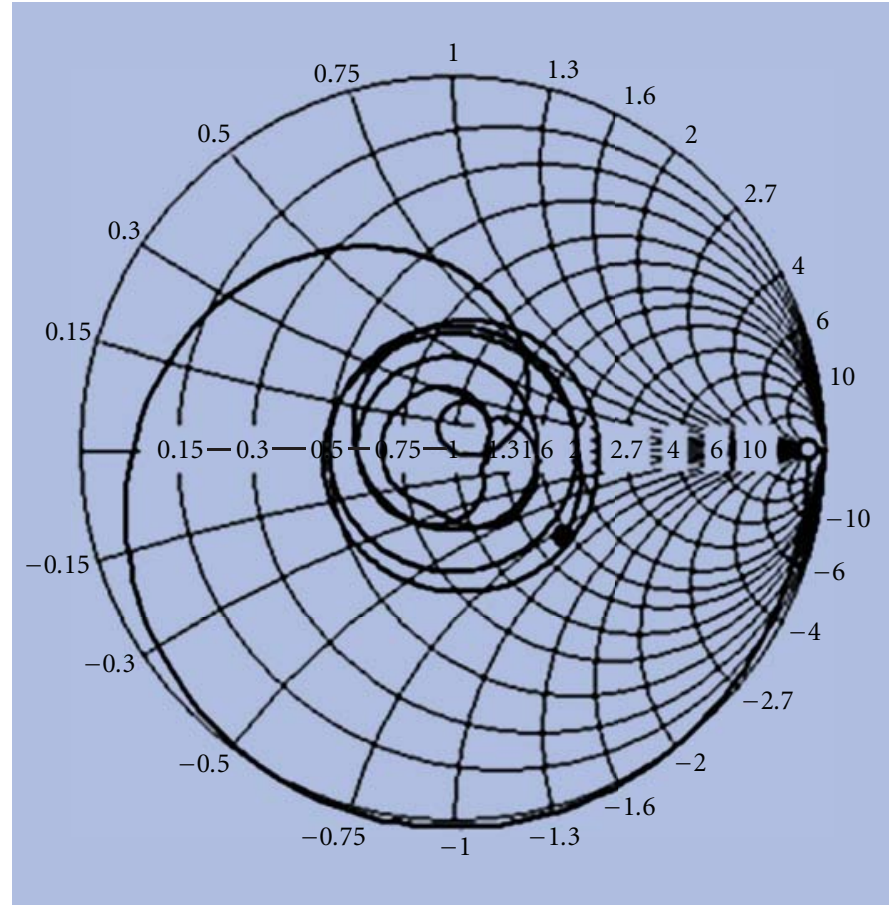

(a)

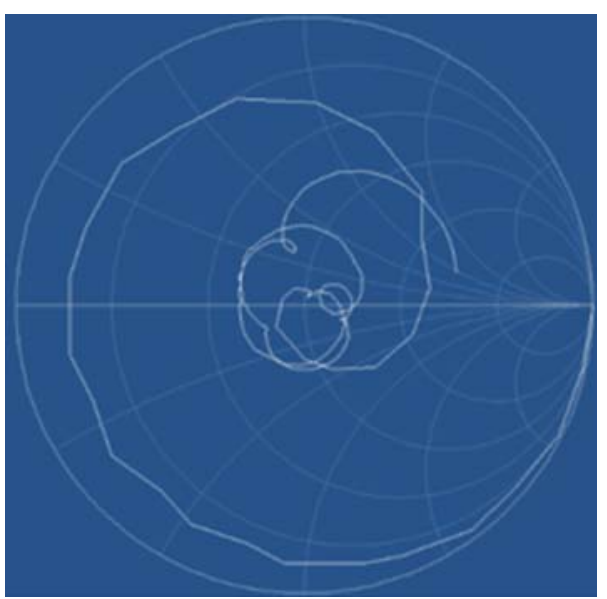

(b)

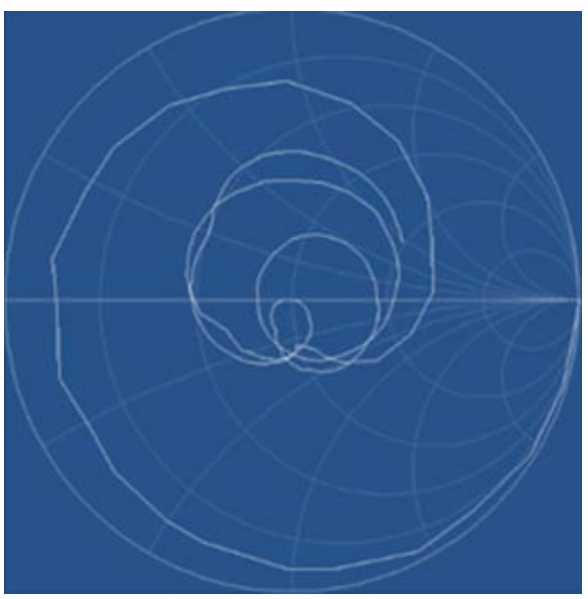

(c)

Figure 5: Comparison between simulated and measured results of the input impedance locus using smith chart. (a) Simulated antenna using copper conducting sheet, (b) measured results of copper conducting sheet, and (c) measured results of Shieldit conducting fabric.

2.2. Conducting Materials. A systematic study was demonstrated using two types of conducting materials. Firstly, copper conducting sheet with a thickness of $0.03 \mathrm{~mm}$ is used in UWB antenna design and numerical analyses for the sake of preliminary design investigation. After that, another type of conducting material (Shieldit conducting fabric) with a thickness of $0.17 \mathrm{~mm}$ is proposed for investigation. The proposed conducting material which is so called "electrotextile material" seems to be most suitable and convenient for textile wearable antenna applications when compared with the unfeasible features of copper conducting sheet (not possible to be washed, not attractive to the wearer, unable to withstand multiple deformation processes, etc.).
Shieldit conducting fabric is made from strong polyester substrate that is plated with nickel and copper, hence it can perform as high quality flame retardant fabric. The fabric is coated on one side with nonconductive hot melt adhesive which make the attachment process easier by ironing the conducting fabric on to the surface of flannel fabric substrate material. The proposed conducting fabric can be washed as well as its ability to resist temperature up to $200^{\circ} \mathrm{C}$.

\section{Design Consideration}

In general, the design and construction of the UWB planer monopole antenna consist of a circular parch to be placed at 


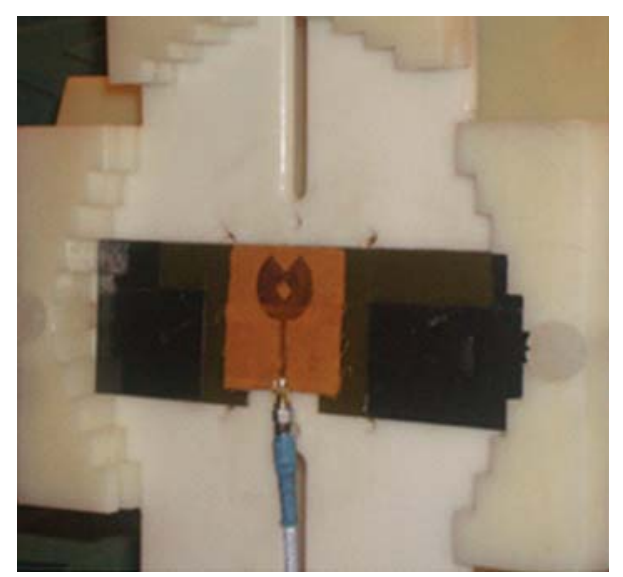

FIGURE 6: Snapshot of measured radiation pattern environment of the UWB textile antenna using copper conducting sheet.

the top of flannel fabric substrate material - a microstrip feed line and a partial ground plane beneath the fabric substrate material. At the starting point in designing UWB fabric antenna, the main patch is initially calculated using (1) below in order to create circular patch at the centre frequency of the UWB spectrum at $7.85 \mathrm{GHz}$. Where $\mathrm{a}$ is the radius of the circular patch antenna in millimetre, $f_{r}$ is the resonance frequency in $\mathrm{GHz}$, and $\varepsilon_{r}$ is the relative permittivity of the textile substrate material:

$$
a=\frac{87.94}{f_{r} \sqrt{\mathcal{E}_{r}}} .
$$

The transmission line feeding technique is introduced in order to connect the main radiating circular patch to the $50 \Omega$ Sub Miniature Version (SMA) connector. Moreover, the partial ground plane was implemented for the proposed antenna design; hence such types of truncated ground plane play an important role in broadband and wideband characteristics of the designed antennas. In particular, the process of ground plane truncation acts as an impedance matching element that controls the impedance bandwidth of the circular patch. Thus, it creates a capacitive load that neutralizes the inductive nature of the patch to produce nearly pure resistive input impedance. According to that, ground plane truncation is achieved by slicing the top portion of the ground plane that covers the radiating patch element to less than half and covers the transmission line section only.

Using CST microwave office software simulation package, the UWB fabric antenna design with copper conducting sheet was initially proposed and numerically analyzed based on the characterization information of flannel fabric substrate material mentioned before. On the contrary, no numerical analysis has been performed for the UWB antenna using Shieldit fabric due to software limitation which allows the setting of copper conducting material only. For further optimizations, one slit at the top of the circular patch and two slits at the bottom of both sides of the main radiating patch are introduced. In addition, a rotated square hole (slot) at the centre of the circular patch is also needed to fine tune the impedance bandwidth at certain frequencies. Thus, with the incorporation of these slits and even the centre slot, the impedance bandwidth throughout the spectrum of the UWB antenna frequencies is well-matched below the level of $-10 \mathrm{~dB}$. A $50 \mathrm{ohm}$ microstrip feed line was provided for the antenna feed; hence the position was determined according to $[23,24]$.

Pursuing the simulation process, both UWB antenna prototypes are fabricated utilizing copper conducting sheet for the first antenna prototype and Shieldit conducting fabric for the second antenna prototype. Figure 1 below demonstrates the CST model along with the geometry and dimensions in millimetre of the current paper design after optimization considering that the design of this antenna has been conducted in air space. The size of the substrate is set to $60 \mathrm{~mm} \times 60 \mathrm{~mm}$ while the patch radius is set to $15 \mathrm{~mm}$ for both proposed and fabricated antenna prototypes and the ground plane size is set to $50 \mathrm{~mm} \times 27 \mathrm{~mm}$. Yet, all these dimensions are shown in Figure 1. Measured results of both fabricated prototypes are compared with the simulated results of copper conducting sheet antenna design.

\section{Textile Antenna Fabrication}

Fabrication process of the wearable textile UWB antenna has been achieved using flannel fabric as substrate material. The copper conducting sheet and Shieldit conducting fabric are used as the conducting materials for the radiating element (front side). However, the ground metal (back side) of both antenna prototypes is made from copper conducting sheet in order to study the effect of conducting materials in more comparable and accurate manner. Moreover, direct metal soldering is used to connect the feed line of the top radiating patch and the ground plane to the SMA coaxial connector in both fabricated antenna prototypes as illustrated in Figure 2. On the other hand, the process of cutting both types of conducting materials turns out to be very critical, hence only a simple cutting tool (scalpel) is used. Thus, the process of making conducting materials edges precise and accurate was essential. On the contrary, the attachment process of both types of conducting materials seemed to be easy, hence the copper conducting sheet which is backed by selfadhesive has been pressed easily and nicely over flannel fabric substrate material. Besides that, Shieldit conducting fabric that is coated on one side with a nonconductive hot melt adhesive has been attached to flannel fabric by ironing and pressing it firmly and easily. Thus, both types of conducting materials turned out to be good solutions as both have been evenly placed and fastened over flannel fabric substrate material. Figures 2(a) and 2(b) demonstrate the fabricated antenna prototypes using copper conducting sheet and Shieldit conducting fabric, respectively.

\section{Results and Discussions}

In order to provide better investigation, this section shall firstly present the simulated and measured reflection coefficient $\left(\left|S_{11}\right|\right)$ and bandwidth results of the UWB antenna 


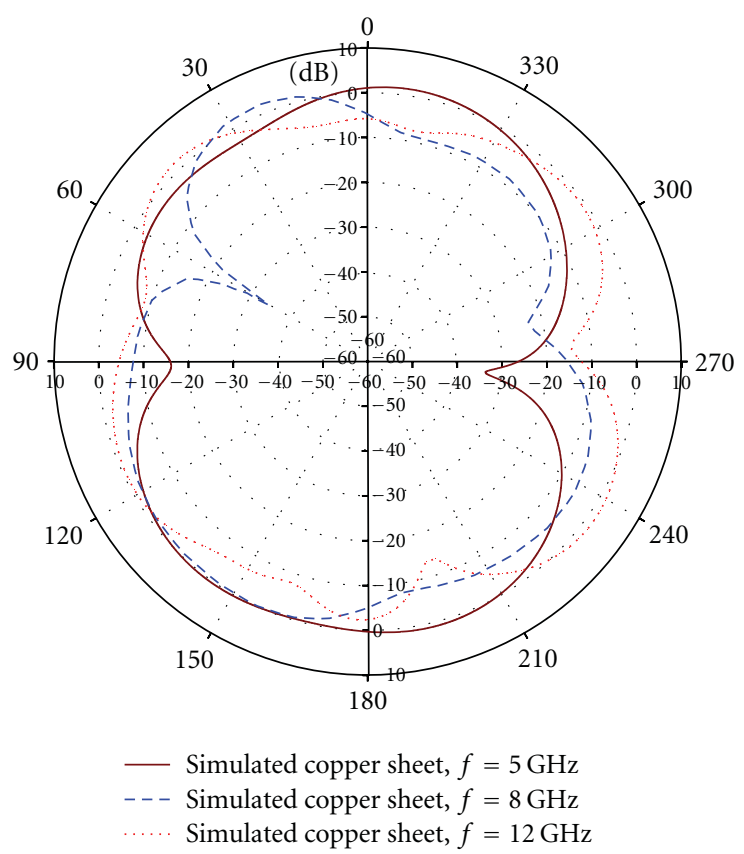

(a) E-Co polar horizontal plane of simulated copper sheet results.

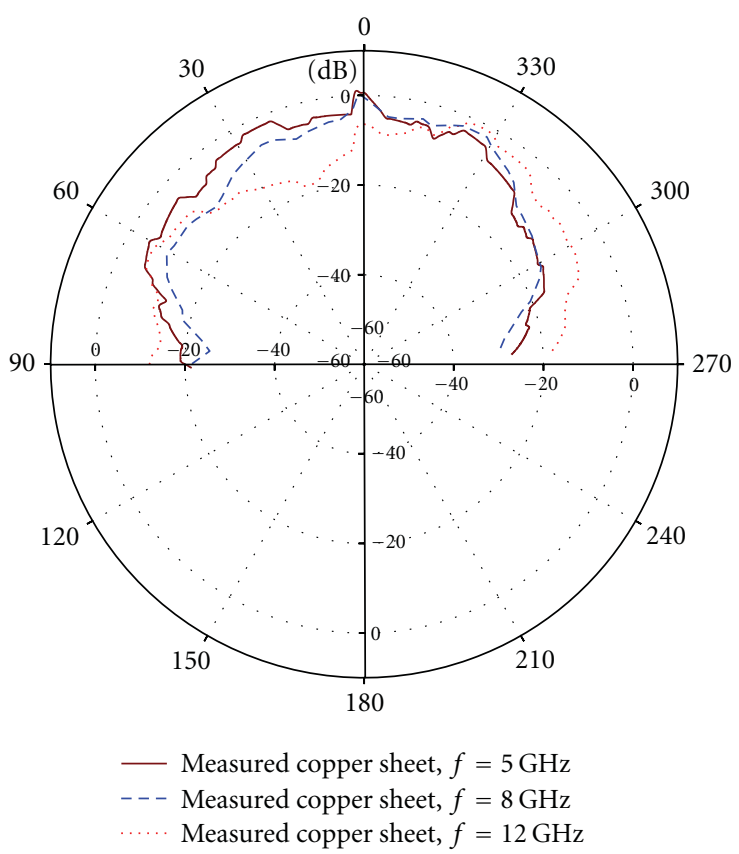

(c) E-Co polar horizontal plane of measured copper sheet results.

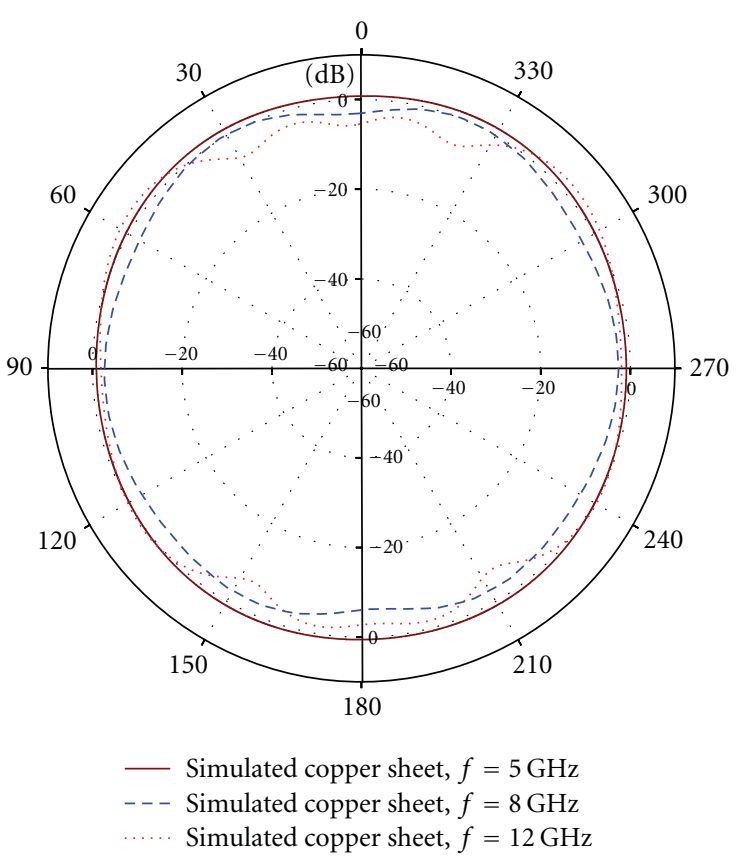

(b) E-Co polar vertical plane of simulated copper sheet results.

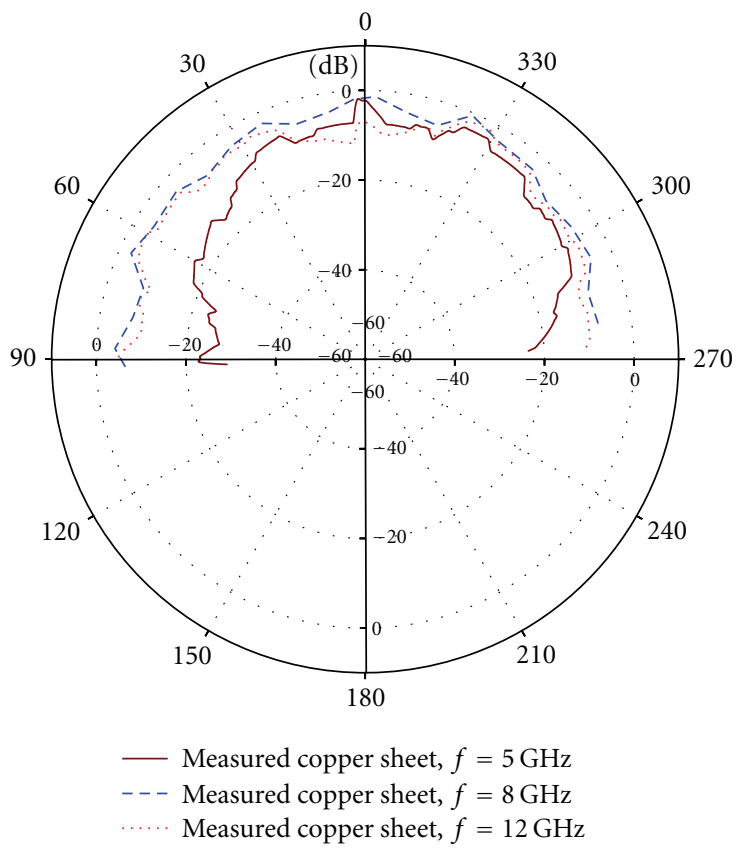

(d) E-Co polar vertical plane of measured copper sheet results.

FIGURE 7: The behaviour of simulated and measured 2D radiation pattern results of the wearable textile UWB antenna design using copper conducting sheet considering three different selected frequency samples that represent the overall achieved bandwidth.

design and then briefly discuss and compare between measured results obtained by both antenna prototypes. After that, simulated and measured radiation patterns results will be considered and briefly discussed. Moreover, effects on the return loss by means of measurements on each fabricated antenna prototype under bent and fully wet conditions will be addressed at the end of this section.
5.1. Simulated and Measured Return Loss Results. The wearable textile UWB antenna simulated design produced good impedance matching with reflection coefficient being below $-10 \mathrm{~dB}$. The bandwidth expands from the lower frequency of $2 \mathrm{GHz}$ till the upper frequency of $15 \mathrm{GHz}$ and thus resulted in BW of $7.5 \%$ over the intended UWB frequency range. According to that, a network analyzer was used to 


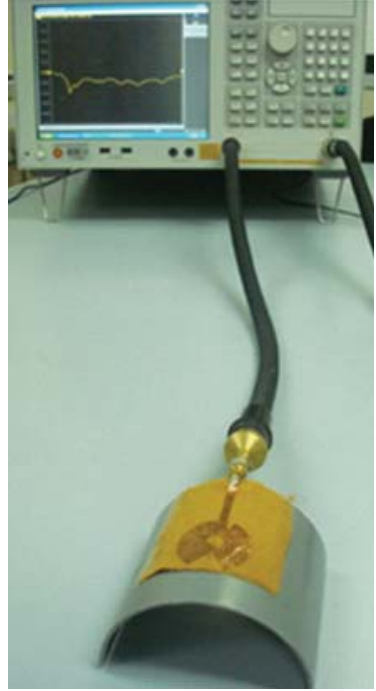

(a) H-convex

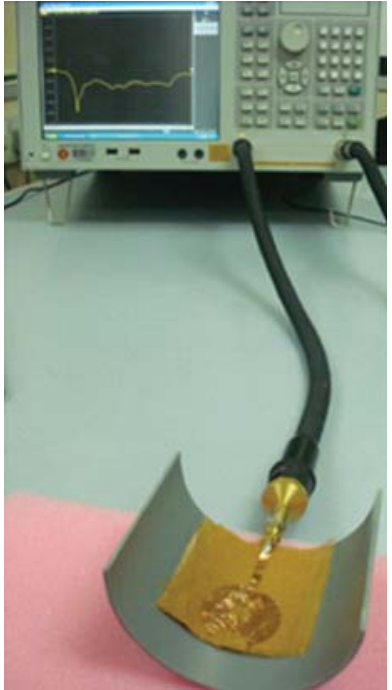

(b) H-concave

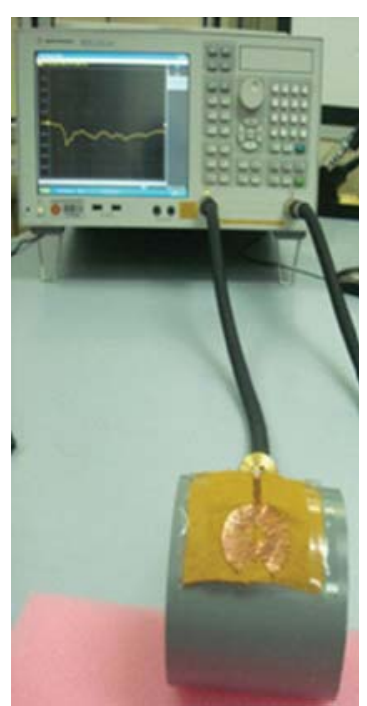

(c) H-convex

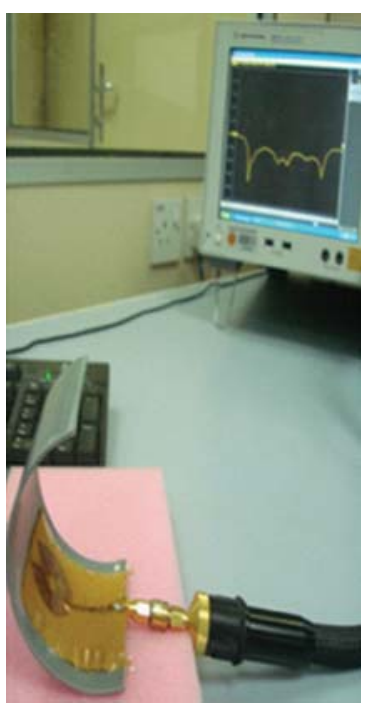

(d) H-concave

FIGURE 8: Snapshots of measurement environment of UWB antenna prototype using copper conducting sheet.

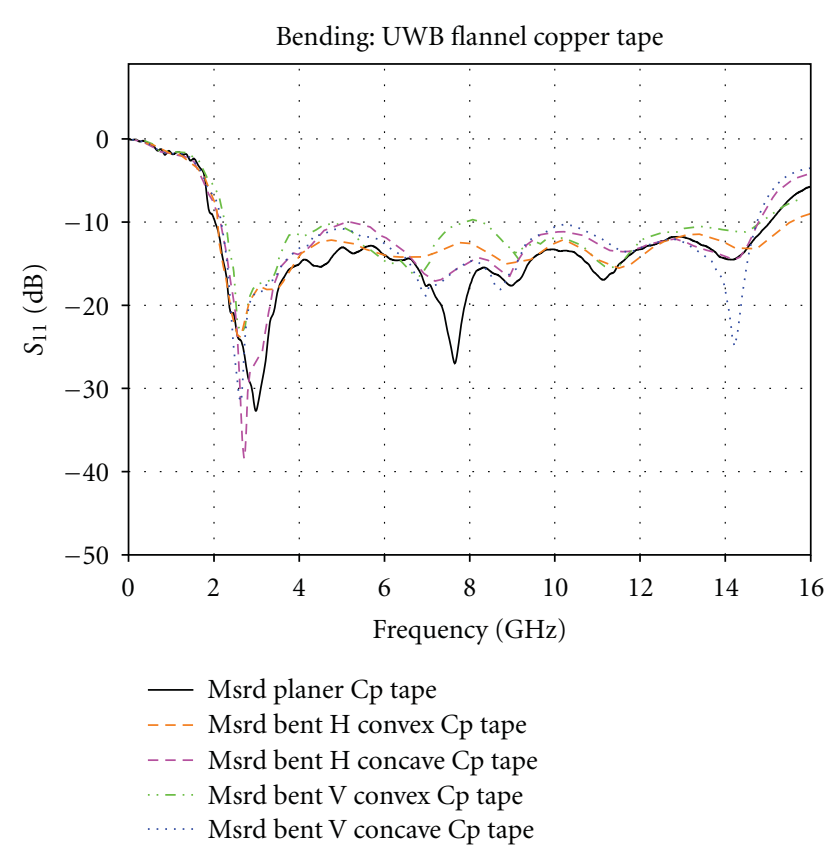

FIGURE 9: Measured $\left(\left|S_{11}\right|\right)$ bending results of UWB antenna prototype using copper conducting sheet.

measure the return loss of both antenna prototypes as a function of frequency. Figure 3 demonstrates snapshots of $\left(\left|S_{11}\right|\right)$ measurement environment of the current paper antenna prototypes, while Figure 4 made a clear verification and comparison between simulated $\left(\left|S_{11}\right|\right)$ results of copper conducting sheet antenna design and measured $\left(\left|S_{11}\right|\right)$ results of both antenna prototypes considering each type of conducting material.
The black solid line demonstrates the simulated $\left(\left|S_{11}\right|\right)$ and bandwidth results of the UWB antenna design using copper conducting sheet, while the blue long dashed line shows the measured $\left(\left|S_{11}\right|\right)$ and bandwidth results of the antenna prototype with copper conducting sheet as well. Moreover, the red dash-dotted line shows the measured return loss and bandwidth results of the UWB antenna prototype utilizing Shieldit conducting fabric.

Although the slight deviation between the presented results, Figure 4 exhibited that $\left(\left|S_{11}\right|\right)$ results were comparable; hence each of the proposed antenna design achieved more than $12 \mathrm{GHz}$ BW within the UWB intended frequency range. Moreover, All UWB antenna prototypes maintained return loss results below the level of $10 \mathrm{~dB}$ with an acceptable and reasonable variation in resonance frequencies depths due to fabrication and measurement tolerances as well as the variation in conductivity related to each conducting material involved in the current investigation. Results indicated that the measured values of flannel fabric dielectric properties were valid enough to provide design information, since the targeted UWB range of frequency is reasonably well met and hence produced comparable measured results.

In addition, Figure 5 expresses the comparison between simulated and measured results of the input impedance locus using smith chart. Figure 5(a) represents the simulated results of the antenna prototype using copper conducting sheet where several loops can be observed on the smith chart within the VSWR $=2$ circles. Conveniently, these loops correspond to locations on smith chart where the antenna's impedance locus crosses the real axis and hence indicated that resonance frequencies are those at which the input impedance is purely real. Similar performances have been achieved for the input impedance measured results for the fabricated antennas utilizing copper conducting sheet, and Shieldit conducting fabric as shown 
in Figures 5(b) and 5(c), respectively. Although the slight deviations between simulated and measured results are visible to some extent, Figure 5 exhibited that all fabricated antennas input impedance results were comparable.

5.2. Simulated and Measured Radiation Pattern Results. Although the limitation of measurement equipments used, the behaviour of 2D simulated and measured radiation pattern components of UWB antenna using copper conducting sheet only is presented, measured and discussed. A snapshot of measured, radiation pattern environment is depicted in Figure 6 where the antenna is located in an anechoic chamber. Furthermore, Figure 7 clarifies the 2D simulated and measured copolar radiation pattern components in the horizontal and vertical planes with three different frequency samples at $5 \mathrm{GHz}, 8 \mathrm{GHz}$, and $12 \mathrm{GHz}$ achieved by copper conducting sheet UWB antenna design of the current paper, where measurement process has been conducted in air space. However, for the sake of better comparison, the measured radiation pattern results were plotted in the range between $-90^{\circ}$ and $+90^{\circ}$. Moreover, the magnitude of the radiation pattern has been normalized to simplify the viewing of measured results.

Figures 7(a) and 7(b) represent the simulated horizontal and vertical planes copolar radiation pattern components respectively of UWB antenna design using copper conducting sheet. On the other hand, the measured copolar radiation pattern components of the fabricated antenna prototype using copper conducting sheet representing the horizontal and vertical planes respectively are demonstrated in Figures $7(\mathrm{c})$ and $7(\mathrm{~d})$.

From Figures 7(a) and 7(b), it can be noticed that the antenna resembles omnidirectional radiation pattern components in the vertical plane whatever the frequency under analysis, while two nulls are visible along the horizontal plane for each frequency under analysis. Moreover, from Figures 7(c) and 7(d), one can observe the slight difference between simulated and measured radiation pattern results in the horizontal and vertical planes. This slight difference can be related to fabrication tolerance and misalignment during measurement setup. However, both results correlate well to each other hence the patterns are similar. Although the other antenna prototype using Shieldit conducting fabric was not measured due to limitations in measurement equipments, the expectation of producing omni directional radiation pattern are high. Thus, these results claimed that future antenna designers need to ensure that wearable telecommunication devices operate properly in the vicinity of human body. In particular, even though UWB antennas known by its lowpower operation and extremely low radiated power, special attention must be paid to the specific absorption rate (SAR) in order to avoid harm to human body.

5.3. Simulated Gain and Efficiency Results. The variations of frequencies versus the gain of the wearable textile UWB antenna design are all demonstrated in Table 1. The maximum gain achieved was about $4.8 \mathrm{~dB}$ at $10 \mathrm{GHz}$. In contrast, the highest percentage of efficiency reached $95 \%$ at $6 \mathrm{GHz}$
TABLE 1: Gain and efficiency simulated results of textile uwb antenna design.

\begin{tabular}{lcc}
\hline $\begin{array}{l}\text { Frequency } \\
(\mathrm{GHz})\end{array}$ & Gain $(\mathrm{dB})$ & $\begin{array}{c}\text { Efficiency } \\
(\%)\end{array}$ \\
\hline 2 & 2.6 & 92 \\
3 & 3.6 & 93 \\
4 & 3.0 & 93 \\
5 & 2.8 & 94 \\
6 & 3.4 & 95 \\
7 & 4.2 & 94 \\
8 & 4.0 & 92 \\
9 & 4.2 & 95 \\
10 & 4.8 & 91 \\
11 & 4.3 & 89 \\
12 & 3.9 & 91 \\
13 & 4.0 & 92 \\
14 & 4.0 & 91 \\
15 & 4.0 & 85 \\
\hline
\end{tabular}

and $9 \mathrm{GHz}$. However, the lowest efficiency was about $85 \%$ at $15 \mathrm{GHz}$. Consequently, results showed that this present paper design has low power consumption due to the achievement of gain results that was less than $5 \mathrm{~dB}$ in most range of frequencies between $3 \mathrm{GHz}$ and $15 \mathrm{GHz}$. In addition, the efficiency of the antenna could be considered vast compared to commercial antennas.

5.4. Effects of Antenna Bending on Measured Return Loss. In a realistic on-body application, the antenna is supposed to be integrated into a suit, and accordingly it will be subject to bending and wetness. Therefore, the effects of bending by means of measurements on both proposed UWB antenna prototypes are investigated. Both antenna prototypes are tested on polystyrene cylinder with a diameter of $80 \mathrm{~mm}$ that corresponds approximately to the typical size of human adult arm. Moreover, each antenna is studied in conventional planer form (as discussed previously) and at four bending positions: horizontal convex, horizontal concave, vertical convex, and vertical concave. Figure 8 demonstrates snapshots of measurement environment of UWB antenna prototype using copper conducting sheet, while Figure 9 illustrates measured $\left(\left|S_{11}\right|\right)$ bending results of copper sheet antenna prototype.

The impedance performances of UWB antenna with copper sheet considering all bent positions are nearly the same with slight fluctuations in return loss when compared with measured planer position. According to that, results indicated that UWB antenna with copper conducting sheet functions satisfactorily under most bending conditions. However, further investigations need to be performed in order to study the effect of severe bending angles as well as crumbling effect on antenna performances.

On the other hand, similar investigations have been performed on the UWB antenna prototype using Shieldit conducting fabric. Figure 10 demonstrates snapshots of 


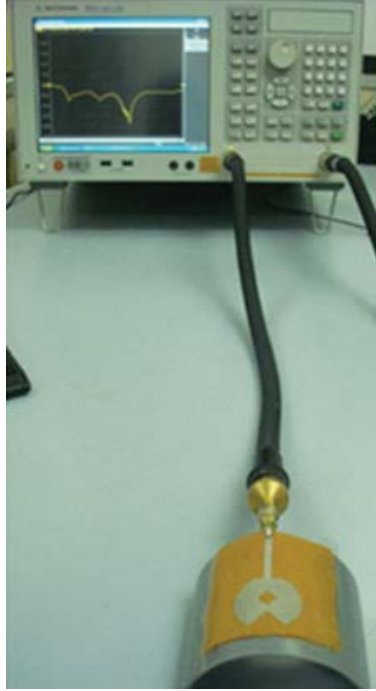

(a) H-convex

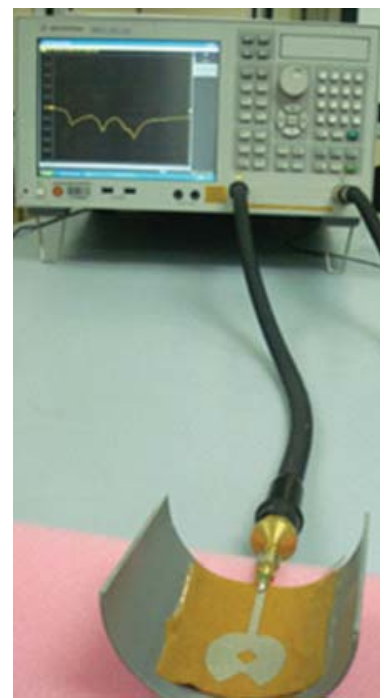

(b) H-concave

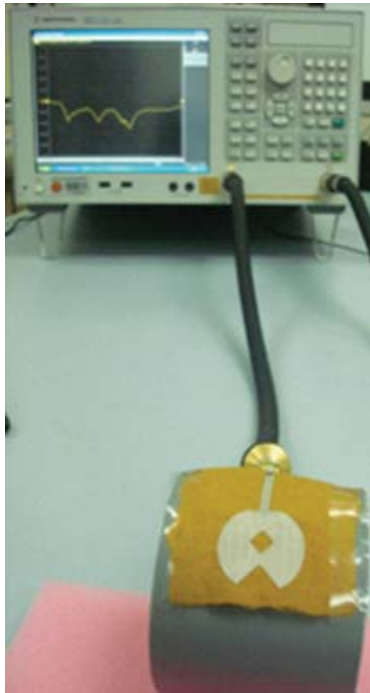

(c) H-convex

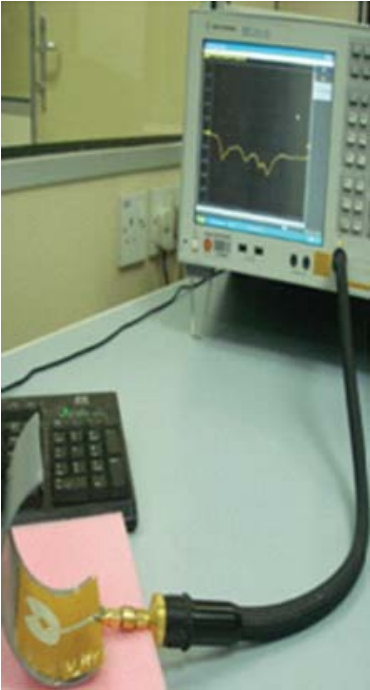

(d) H-concave

FIgURE 10: Snapshots of measurement environment of UWB antenna prototype using Shieldit conducting fabric.

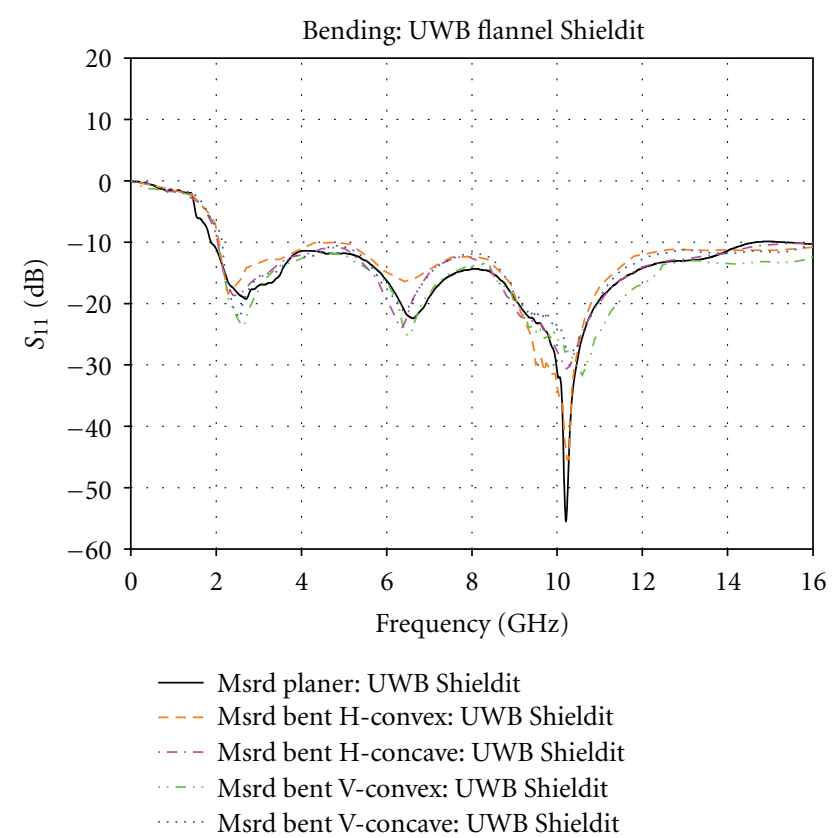

FIGURE 11: Measured $\left(\left|S_{11}\right|\right)$ bending results of UWB antenna prototype using Shieldit conducting fabric.

measurement environment of UWB antenna prototype using Shieldit conducting fabric, while Figure 11 illustrates the measured bending results of Shieldit conducting fabric antenna prototype. The impedance performances of UWB antenna with Shieldit conducting fabric considering all bent positions are almost identical with slight fluctuations in return loss when compared with the measured flat position. According to that, results indicated that UWB antenna with Shieldit conducting fabric functions satisfactorily under most bending conditions. However, further investigations need to be performed in order to study the effect of severe bending angles as well as crumbling effect on the proposed antenna performances.

5.5. Antenna Performance on Wet Conditions. Water has got a very high dielectric constant as compared to any fabric substrate material. Thus, when an antenna absorbs water, the moisture might change the antenna performance parameters significantly. The higher dielectric constant of water dominates the antenna performance by changing the resonant frequency. According to that, wearable antennas need to be measured considering wetness aspects.

In the current paper, measured results of four different states considering wetness, dampness and even when fully dried again for the UWB antenna prototype using copper conducting sheet and Shieldit conducting fabric are depicted in Figures 12 and 13, respectively.

Moreover, Figures 14 and 15 illustrate, the measured $\left(\left|S_{11}\right|\right)$ results of UWB antenna prototypes using copper conducting sheet and Shieldit conducting fabric, respectively. Firstly, the textile antenna prototype was kept under water for more than three hours and measured inside water. After that, antenna under test was taken out of the water and measured immediately. Then, the antenna has been dried up using dry towel and measured; hence this state is recalled as approximately dry condition. Finally, the performance of the integrated antenna was tested when fully dried again.

From Figures 14 and 15, the blue solid line demonstrates the planner antenna performance when it was dry (before putting the antenna inside water) and after completely dried, while the dotted line shows the antenna performance inside water (completely wet). On the other hand, the short dashed line represents the immediately wet antenna state; hence the antenna was measured when it has been taken immediately out of water. Moreover, the dash-dotted line illustrates the 


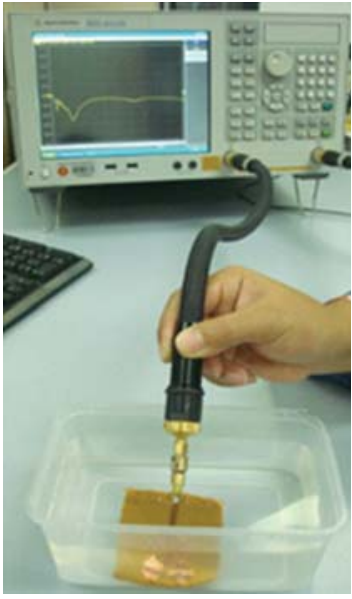

(a) Inside water

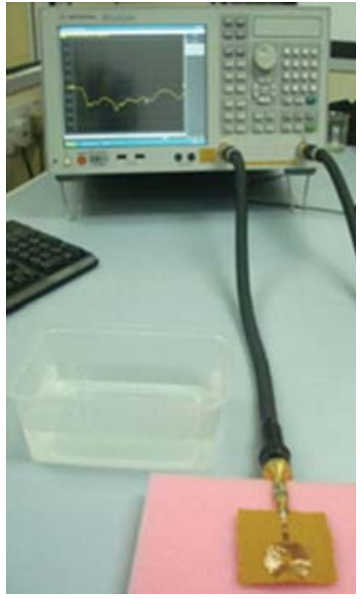

(b) Immediately wet

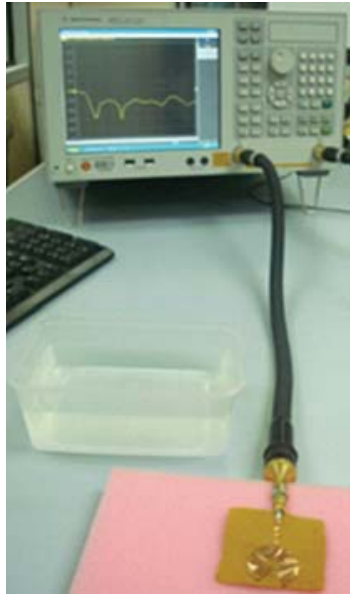

(c) Approximately dried

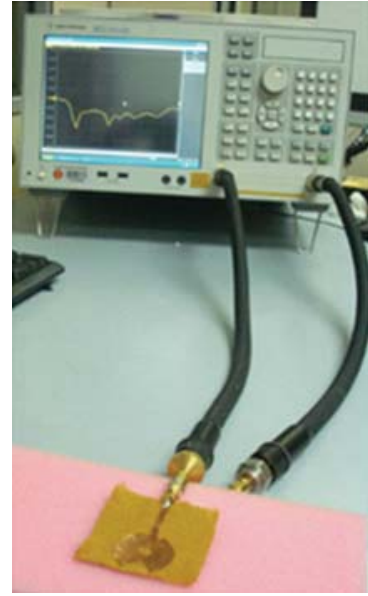

(d) Completely dry

FIGURE 12: Snapshots of measured results of UWB antenna prototype using copper conducting sheet considering different states of wetness, dampness, and fully dried.

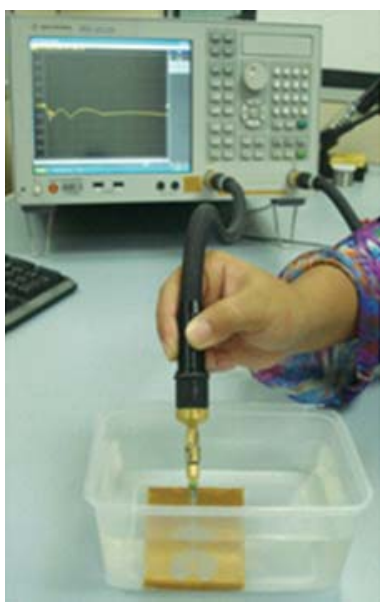

(a) Inside water

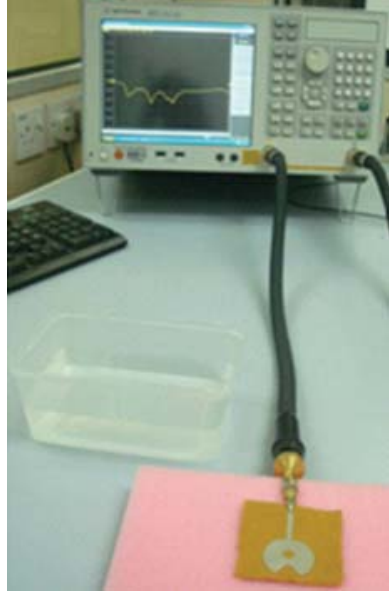

(b) Immediately wet

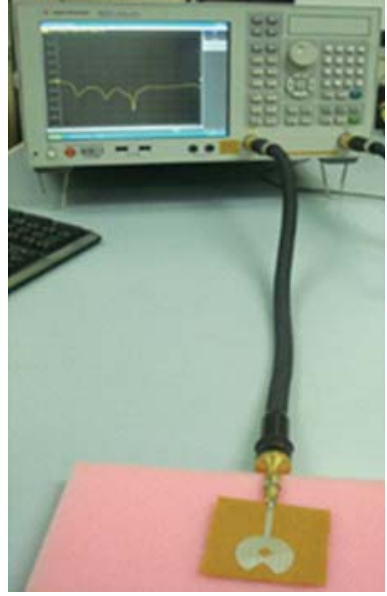

(c) Approximately dried

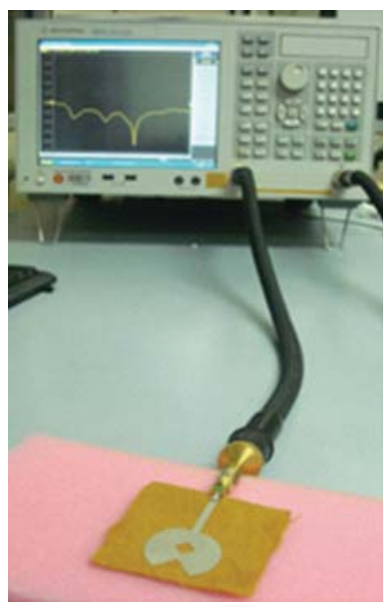

(d) Completely dry

FIGURE 13: Snapshots of measured results of UWB antenna prototype using Shieldit conducting fabric considering different states of wetness, dampness, and fully dried.

performance of the antenna after it has been dried (using dry towel) and measured.

In the case of copper sheet antenna prototype, the inside water and immediately wet measurements indicated that the antenna was able to resonate with an expected degradation in resonance frequency while the frequency depth maintained to be below $-8 \mathrm{~dB}$ in all UWB frequency range. After drying the antenna with dry towel, measured results (approximately dry) indicated that the antenna showed good impedance matching performances from $2 \mathrm{GHz}$ up to $15 \mathrm{GHz}$ with some negligible effect of water and moisture on antenna performance. Finally, results reported that the performance before and after wetness as the antenna has been fully dried remained unchanged.

However, Shieldit fabric antenna prototype is measured inside water and hence results indicated that the antenna is able to resonate with an expected degradation in resonance frequency while the frequency depth maintained to be below $-8 \mathrm{~dB}$ in all UWB frequency range. Although the slight deviation, measured results of immediately wet state, approximately dry state, and fully dried condition showed that the antenna performances remained unchanged when compared with measured results of planer state before wetness. Results indicated that the minor effect of water and moisture on antenna performance makes the proposed antenna suitable for humid conditions as well.

\section{Conclusion}

Fully textile antennas and specially electrotextile materials themselves have strong potential to be used as antennas for transmission purposes in garments. In the current manuscript, UWB wearable antenna using fully textile materials are proposed and presented. The proposed antenna 


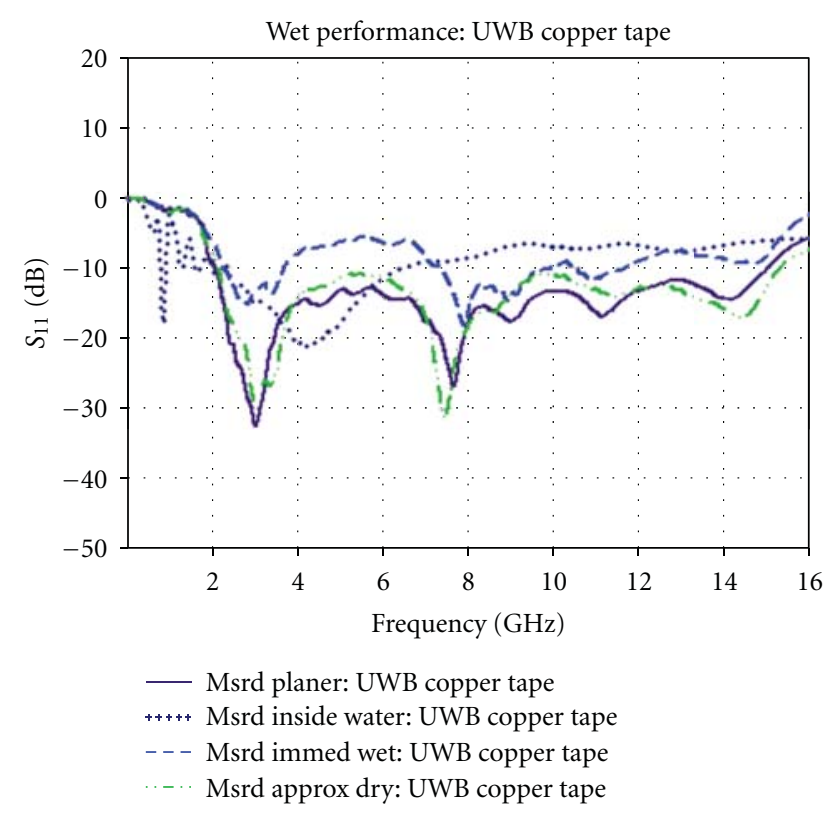

FIgURE 14: Measured $\left(\left|S_{11}\right|\right)$ results of UWB antenna prototype using copper conducting sheet considering several wet conditions.

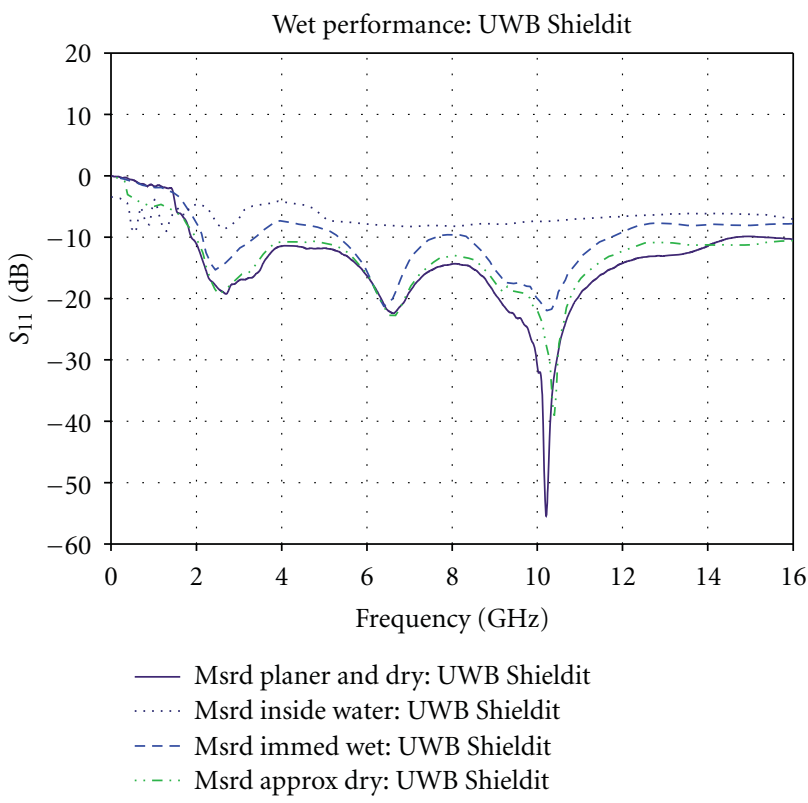

FIGURE 15: Measured $\left(\left|S_{11}\right|\right)$ results of UWB antenna prototype using Shieldit conducting fabric considering several wet conditions.

design provides more than $12 \mathrm{GHz}$ bandwidth with such compact size and flexible materials and showed good measured return loss $\left(\left|S_{11}\right|\right)$ characteristics, omnidirectional patterns, as well as adequate gain and efficiency results. Moreover, effects of bending and wetness by means of measurements on both proposed UWB antenna performances are investigated. Results indicated that flannel fabric can act and perform as good candidate for textile wearable applications and possible to replace rigid board substrate materials. Besides that, the fabricated antennas using textile conducting materials complied wearable antennas requirements by providing the wearer with compact antenna prototypes, flexible materials, ease of washing as well as ensuring the attractiveness of wearable devices. However, washable packaging of the electronics and durable interconnections remain major challenges to be tackled for all wearable electronics. Consequently, evaluation of long-term behaviour, durability and system performance after repeated wetness and laundering should invariably be considered in research tasks.

\section{Acknowledgments}

Authors wish to acknowledge the support of Ministry of Higher Education (MOHE), Research Management Centre (RMC), Radio Communication Engineering Department (RaCED), Faculty of Electrical Engineering, Universiti Teknologi Malaysia for supporting this research work under Grant no. 4L008 and 74578. The authors also wish to thank Sudan University of Science and Technology for supporting this research paper.

\section{References}

[1] L. van Langenhove, Smart Textiles for Medicine and Healthcare, CRC Press, Cambridge, UK, 2007.

[2] A. R. Chandran and W. G. Scanlon, "Dual-band low profile antennas for body-centric communications," in Proceedings of the International Workshop on Antenna Technology: Small Antennas, Innovative Structures and Materials (iWAT'10), pp. 1-4, Lisbon, Portugal, March 2010.

[3] H. Rogier, C. Hertleer, L. Vallozzi, P. van Torre, F. Declercq, and M. Moeneclaey, "Indoor off-body communication based on a textile multi-antenna system integrated in clothing for rescue workers," in Proceedings of the 2nd IET Seminar on Antennas and Propagation for Body-Centric Wireless Communications, pp. 1-36, London, UK, April 2009.

[4] B. Sanz-Izquierdo, J. C. Batchelor, and M. I. Sobhy, "Compact UWB wearable antenna," in Proceedings of th 3 rd Loughborough Antennas and Propagation Conference (LAPC '07), pp. 121-124, Loughborough, UK, April 2007.

[5] L. Januszkiewicz, S. Hausman, and T. Kacprzak, "Textile bodyworn exponentially tapered vee antenna," Electronic Letters, vol. 42, no. 3, 2007.

[6] N. Chahat, M. Zhadobov, R. Sauleau, and K. Mahdjoubi, "Improvement of the on-body performance of a dual-band textile antenna using an EBG structure," in Proceedings of the 6th Loughborough Antennas and Propagation Conference (LAPC '10), pp. 465-468, Loughborough, UK, November 2010.

[7] S. Barbarino and F. Consoli, "UWB circular slot antenna provided with an inverted-L notch filter for the $5 \mathrm{GHz}$ WLAN band," Progress in Electromagnetics Research, vol. 104, pp. 1-13, 2010.

[8] M. A. Matin, Ultra Wideband Communications: Novel Trends in Antennas and Propagations, InTech, Rijeka, Croatia, 2011.

[9] I. Minin, Microwave and Millimeter Wave Technologies: Modern UWB Antennas and Equipment, InTech, Uttarakhand, India, 2010.

[10] M. A. R. Osman, M. K. A. Rahim, M. Azfar, A. K. Kamardin, F. Zubir, and N. A. Samsuri, "Performance and evaluation of 
ultra-wideband wearable textile antenna," in Proceedings of the IEEE European Conference on Antennas and Propagation (EuCAP '11), Rome, Italy, April 2011.

[11] P. van Torre, L. Vallozzi, C. Hertleer, H. Rogier, M. Moeneclaey, and J. Verhaevert, "Indoor Off-Body wireless MIMO communication with dual polarized textile antennas," IEEE Transactions on Antennas and Propagation, vol. 59, no. 2, pp. 631-642, 2011.

[12] S. Sankaralingam and B. Gupta, "Determination of dielectric constant of fabric materials and their use as substrates for design and development of antennas for wearable applications," IEEE Transactions on Instrumentation and Measurement, vol. 59, no. 12, pp. 3122-3130, 2010.

[13] P. J. Soh, G. A. E. Vandenbosch, V. Volski, and H. M. R. Nurul, "Characterization of a simple broadband textile planar inverted-F antenna (PIFA) for on body communications," in Proceedings of the 20th International Conference on Applied Electromagnetics and Communications (ICECom '10), pp. 1-4, Dubrovnik, Croatia, September 2010.

[14] S. Zhu and R. J. Langley, "Dual-band wearable antennas over EBG substrate," IET Electronics Letters, vol. 43, no. 3, pp. 141143, 2007.

[15] M. Tanaka and J. H. Jang, "Wearable microstrip antenna," in Proceedings of the IEEE International Symposium on Antennas and Propagation and URSI North American Radio Science Meeting, Columbus, Ohio, USA, June 2003.

[16] B. Sanz-Izquierdo, F. Huang, and J. C. Batchelor, "Covert dualband wearable button antenna," Electronics Letters, vol. 42, no. 12, pp. 668-670, 2006.

[17] R. Langley and S. Zhu, "Dual band wearable antenna," in Proceedings of the Loughborough Antennas and Propagation Conference (LAPC '08), pp. 14-17, Loughborough, UK, March 2008.

[18] M. A. R. Osman, M. K. A. Rahim, S. H. S. Ariffin, and S. K. S. Yuosf, "The investigation of flannel fabric layers," in Proceedings of the International Symposium on Antennas and Propagations, Macao, China, November 2010.

[19] M. Klemm and G. Troester, "Textile UWB antennas for wireless body area networks," IEEE Transactions on Antennas and Propagation, vol. 54, no. 11, pp. 3192-3197, 2006.

[20] A. Lazaro, D. Girbau, and R. Villarino, "Weflighted centroid method for breast tumor localization using an UWB radar," Progress in Electromagnetics Research B, no. 24, pp. 1-15, 2010.

[21] S. Gao, S. Xiao, D. Jin, and B. Z. Wang, "WideBand antenna for ultra-wideband (UWB) body-centric wireless communications," in Proceedings of the IEEE International Conference on Ultra-Wideband (ICUWB '10), pp. 1-4, Nanjing, China, September 2010.

[22] P. Sungmee and S. Jayaraman, "Wearable biomedical systems: research to reality," in Proceedings of the IEEE International Conference on Portable Information Devices (PORTABLE '07), Orlando, Fla, USA, March 2007.

[23] C. A. Balanis, Antenna Theory Analysis and Design, John Wiley \& Sons, New York, NY, USA, 2005.

[24] W. L. Stutzman and G. A. Thiele, Antenna Theory and Design, John Wiley \& Sons, New York, NY, USA, 2nd edition, 1998. 

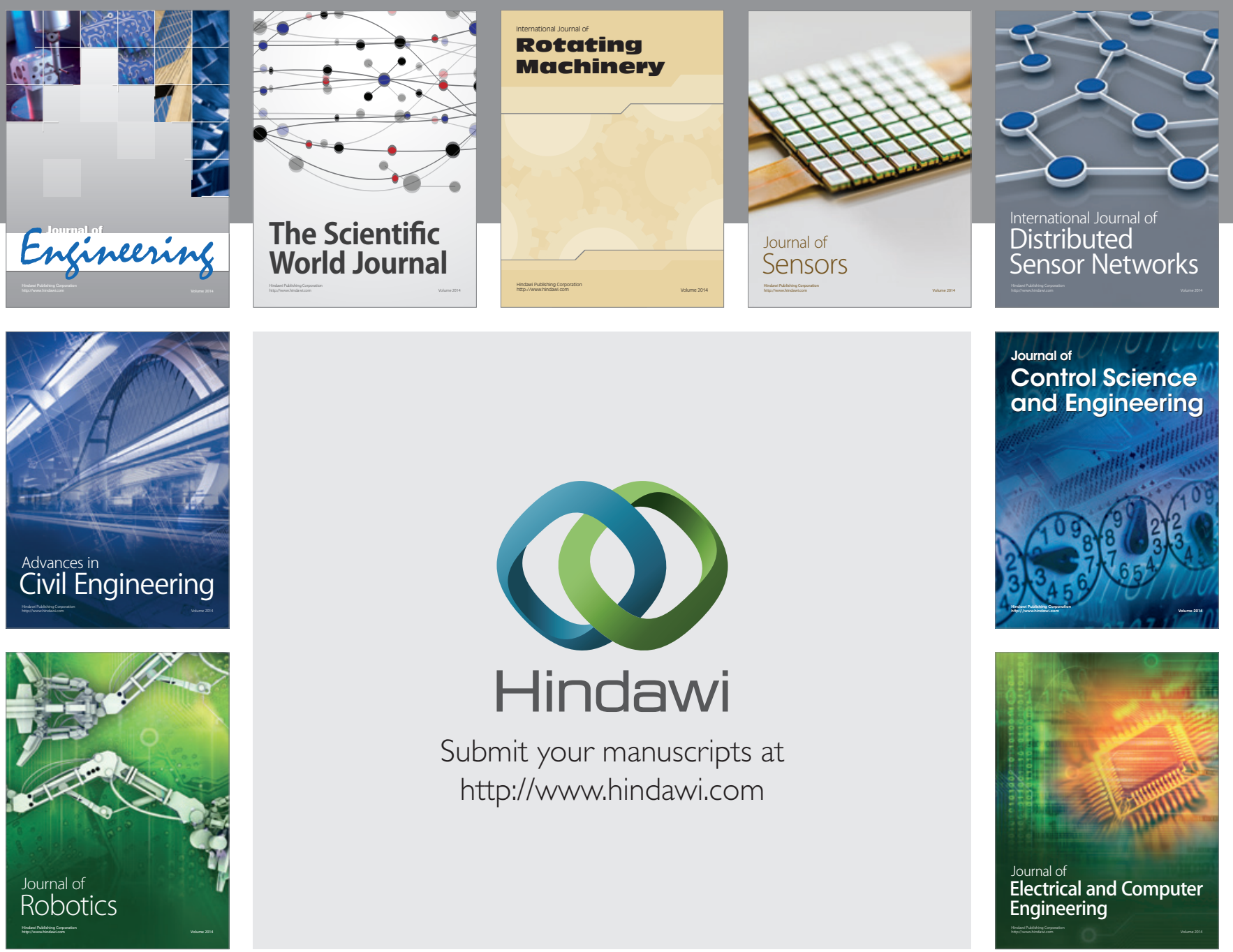

Submit your manuscripts at

http://www.hindawi.com
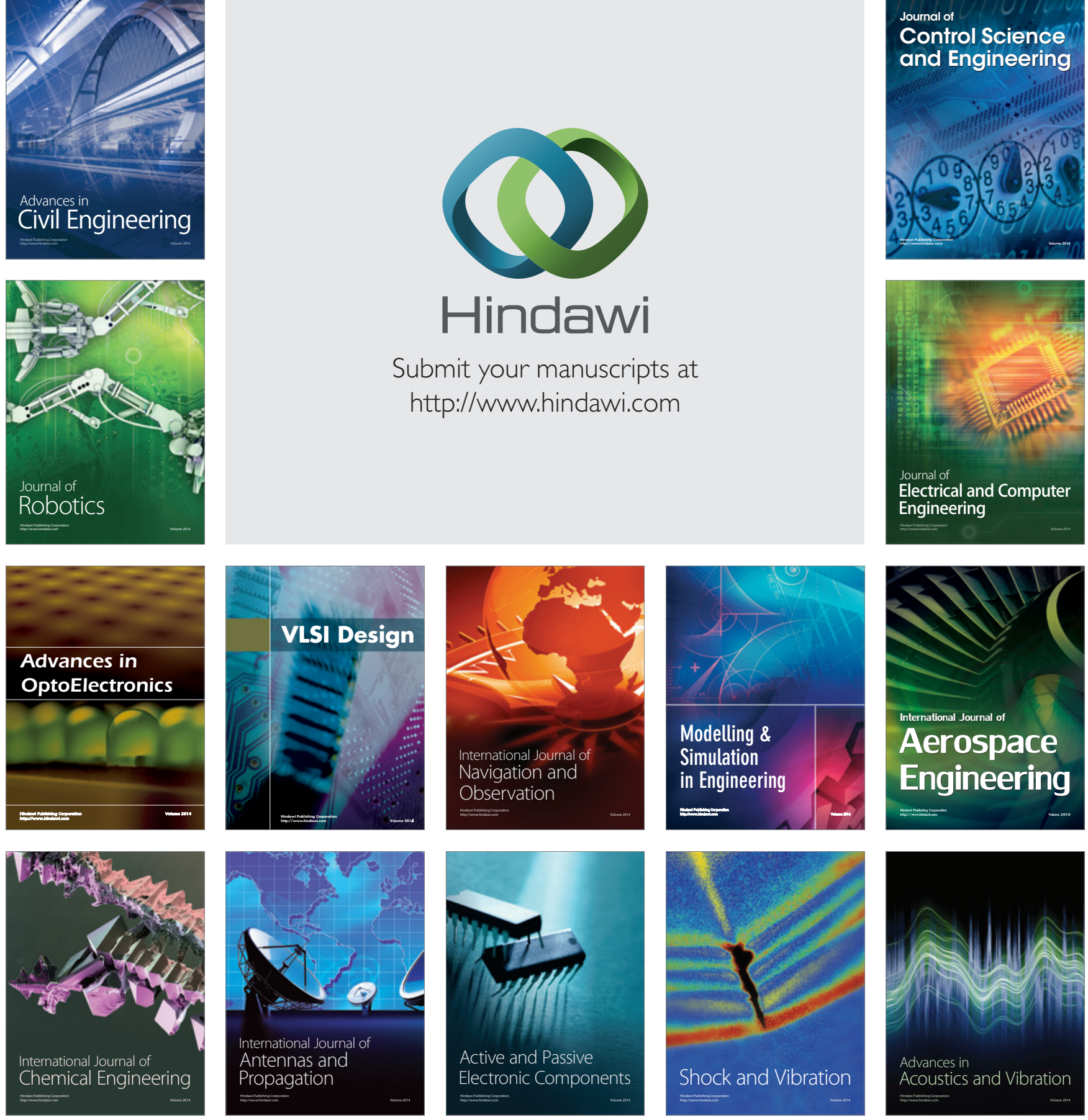